\title{
PERCEPÇÃO DAS PUÉRPERAS SOBRE A ASSISTÊNCIA PRESTADA PELA EQUIPE DE SAÚDE NO PRÉ-NATAL
}

\author{
Sônia Maria Vieiraํ, Lisnéia Fabiani Bock², Denise Azambuja Zocche ${ }^{3}$, Camila Utz Pessota ${ }^{4}$
}

\begin{abstract}
${ }^{1}$ Enfermeira do Grupo Hospitalar Conceição de Porto Alegre. Rio Grande do Sul, Brasil. E-mail: sonia.mvieira@globo.com
${ }^{2}$ Doutoranda em Enfermagem do Programa de Pós-Graduação em Enfermagem da Universidade Federal de Santa Catarina. Docente do Curso de Enfermagem do Centro Universitário Metodista do Sul. Rio Grande do Sul, Brasil. E-mail: ffabibock@ hotmail.com

${ }^{3}$ Doutoranda do Programa de Pós-Graduação em Enfermagem da Universidade Federal do Rio Grande do Sul. Docente do Curso de Enfermagem do Centro Universitário Metodista do Sul. Rio Grande do Sul, Brasil. E-mail: denise.azambuja@ metodistadosul.edu.br

${ }^{4}$ Enfermeira. Especialista em Saúde da Família. Docente do Curso de Enfermagem do Centro Universitário Metodista do Sul. Rio Grande do Sul, Brasil. E-mail: utzcamila@gmail.com
\end{abstract}

RESUMO: Trata-se de uma pesquisa qualitativa e descritiva, objetivando identificar de que modo as puérperas usuárias de um serviço público de saúde de Porto Alegre percebem a assistência prestada pela equipe de saúde no pré-natal e o que pensam sobre o acesso, o acolhimento e o atendimento recebido durante esse período. Realizamos entrevista, em setembro de 2009, com 11 puérperas, em uma maternidade de Porto Alegre-RS. Os dados coletados foram analisados e discutidos à luz das recomendações do Ministério da Saúde para o atendimento no pré-natal, e estruturados em cinco categorias: adesão ao pré-natal; acesso, acolhimento e humanização; acompanhamento do profissional de saúde no pré-natal; a visibilidade do enfermeiro no pré-natal; e finalizando o pré-natal na maternidade. Concluímos que, apesar do Programa de Humanização no Pré-Natal e Nascimento e do esforço da instituição pesquisada em adequar as políticas de saúde no seu cotidiano, ainda existem lacunas em relação à assistência humanizada e holística à gestante e puérpera.

DESCRITORES: Cuidado pré-natal. Saúde da mulher. Período pós-parto. Equipe de assistência ao paciente. Cuidados de enfermagem.

\section{PERCEPTIONS AMONG PREGNANT WOMEN ON PRE-NATAL CARE PROVIDED BY THE HEALTH TEAM}

\begin{abstract}
This is a qualitative and descriptive study whose aim is to identify in what way pregnant women users of the Brazilian public health service perceived of the care provided by the prenatal health care team, examining the conditions, care, and assistance received. We conducted interviews in September of 2009 with 11 mothers in a maternity hospital in Porto Alegre, RS, Brazil. The data was analyzed and discussed in light of the Brazilian Ministry of Health's recommendations for pre-natal care then structured into five categories: adherence to prenatal care; access, reception, and humanization; monitoring the health professional in prenatal; the visibility of nurses in prenatal care; and finalizing prenatal maternity. We conclude that despite the Humanization Program in Prenatal and Delivery and the effort of the research institution to adequate health policies into their daily lives, there are still gaps with respect to humane and holistic care for pregnant and puerperal women.
\end{abstract}

DESCRIPTORS: Prenatal care. Women's health. Postpartum period. Patient care team. Nursing care.

\section{LA PERCEPCIÓN DE LAS PUÉRPERAS SOBRE LA ASISTENCIA PRESTADA POR EL EQUIPO DE SALUD EN EL PRENATAL}

RESUMEN: La presente es una investigación cualitativa y descriptiva, con el objetivo de identificar cómo las puérperas que acuden a un servicio público de salud perciben la asistencia prestada por parte del equipo de salud en el prenatal. Para el estudio se analizaron las condiciones, el cuidado y la ayuda recibida. Se hicieron entrevistas con 11 puérperas, en septiembre de 2009, en una maternidad de Porto Alegre-RS. Los datos se analizaron y discutieron según las recomendaciones del Ministerio de Salud para la atención prenatal, y se organizaron en cinco categorías: la adhesión a la atención prenatal; acceso, atención y humanización; la supervisión del profesional de salud en el período del prenatal; la visibilidad de las enfermeras en la atención prenatal; y la finalización del prenatal en la maternidad. Se concluye que a pesar del Programa de Humanización del Prenatal y Nacimiento y del esfuerzo de la institución investigada por adecuar las políticas de salud en su vida diaria, aún existen brechas en relación a una atención humanizada y holística a las mujeres embarazadas y puérperas.

DESCRIPTORES: Atención prenatal. Salud de la mujer. Periodo de posparto. Equipo de atención al paciente. Atención de enfermería. 


\section{CONSIDERAÇÕES INICIAIS}

A saúde da mulher tem sido um campo de grande preocupação e discussões ao longo de várias décadas. A vivência gestacional é um período muito peculiar na vida de uma mulher, e o nascimento do filho é uma experiência única, portanto, merecem ser tratados de forma singular e especial por profissionais qualificados, pela equipe multiprofissional, por gestores e pelo governo.

O Programa de Humanização no Pré-natal e Nascimento (PHPN) traz estratégias para o atendimento humanizado - como assegurar às gestantes um acesso facilitado ao serviço de saúde, cobertura e qualidade do acompanhamento durante o pré-natal -, como também para a assistência ao parto, ao puerpério, ao binômio mãe-bebê, além de ampliar as ações já existentes pautadas pelo Ministério da Saúde na área de atenção à gestante. ${ }^{1}$

Dados do Ministério da Saúde apontaram em 2005 um coeficiente de mortalidade materna de 54,4 por cem mil nascidos vivos, e, no Rio Grande do Sul, a Secretaria da Saúde registrou em 2006 a ocorrência de 94 mortes relacionadas a gravidez, parto e puerpério, sendo 28 delas na região metropolitana de Porto Alegre. Esses indicadores, quando comparados aos parâmetros estabelecidos pela OMS, mostram-se elevados. ${ }^{1}$

A temática humanização no cuidado e atendimento em saúde à gestante no pré-natal mostra-se relevante no corpo deste estudo, pois a constituição de um atendimento baseado em princípios como a integralidade da assistência, a equidade, a participação social do usuário, entre outros, demanda a revisão de práticas cotidianas, devido às altas taxas de morbimortalidade materna e neonatal.

Diante desse contexto e procurando entender se a assistência oferecida à mulher no pré-natal atende às recomendações do Ministério da Saúde, este estudo visa identificar de que modo as puérperas usuárias de um serviço público de saúde de Porto Alegre percebem a assistência prestada pela equipe de saúde no pré-natal, e o que pensam sobre o acesso, o acolhimento e o atendimento recebido durante esse período.

\section{METODOLOGIA}

Trata-se de um estudo exploratório e descritivo, com abordagem qualitativa, realizado em uma maternidade pública na cidade de Porto Alegre, situada em um hospital público materno-infantil, de grande porte, vinculado à Secretaria Municipal da Saúde do município. A referida maternidade é referência para todo o estado do Rio Grande do Sul no atendimento a mulheres com gestação de alto risco, atendendo também à comunidade em geral, conforme a disponibilidade de vagas oriundas do Sistema Único de Saúde (SUS). A filosofia de trabalho da maternidade está baseada na humanização do cuidado integral à gestante no período do pré-natal, parto e puerpério.

Como instrumento de coleta de dados, utilizou-se a entrevista semiestruturada, com seis questões abertas. A enfermeira responsável pelo turno de trabalho auxiliou na identificação dos sujeitos conforme os critérios de inclusão do estudo. Utilizou-se um espaço individual na própria unidade da maternidade, em um período de tempo de aproximadamente 30 minutos.

As falas foram gravadas e ouvidas pela pesquisadora e, posteriormente, transcritas na íntegra, para interpretação e análise temática. ${ }^{2}$

O estudo foi previamente aprovado pelo Comitê de Ética e Pesquisa do Centro Universitário Metodista do IPA, sob o protocolo de $n^{\circ} 224 / 2009$, e pela Prefeitura Municipal de Porto Alegre, sob o protocolo de $n^{\circ} 22 / 2009$. Participaram 11 mulheres, puérperas e multíparas, com mais de 18 anos. Foram excluídas as que estivessem recebendo o primeiro atendimento no local da pesquisa e as que tivessem alguma deficiência mental ou de comunicação verbal de grau incapacitante.

As participantes assinaram um Termo de Consentimento Livre e Esclarecido, atendendo a Resolução 196/96, com informações pertinentes ao estudo. ${ }^{3}$ Foram identificadas com nomes de flores: Jasmim, Hortência, Rosa, Violeta, Cravo, Orquídea, Dália, Lírio, Margarida, Crisântemo e Azaléia.

\section{RESULTADOS E DISCUSSÃO}

Para facilitar a compreensão das falas, seguindo o rigor metodológico escolhido para análise, foram elaboradas cinco categorias: 1) Adesão ao pré-natal; 2) Acesso, acolhimento e humanização; 3) Acompanhamento dos profissionais de saúde no pré-natal; 4) A visibilidade do enfermeiro no acompanhamento do pré-natal; e 5) Finalizando o pré-natal na maternidade.

\section{Primeira categoria: adesão ao pré-natal}

Através das falas, observamos que as puérperas consideram importante a realização do pré-natal, e que a empatia da gestante com os profissionais e o serviço terá influência na adesão às consultas e assistência integral. 
[...] desconfiei que estava grávida e fui no posto de saúde fazer uma consulta, a enfermeira me recebeu bem [...] a partir daí, agendamos para fazer uma consulta por mês (Jasmim).

[...] no início foi bom, fiz no postinho perto de minha casa, quando achei que estava grávida fui lá e a enfermeira escutou o coraçãozinho do bebê e batia bem forte [...]. Lá fiz cinco consultas (Hortência).

O PHPN estabelece que a captação da gestante pelo serviço de saúde deve ocorrer em até 120 dias da gestação. A grande variação no tempo transcorrido até a chegada ao serviço público de saúde está associada à disponibilidade de acesso aberto pelo serviço, como a oferta de exame confirmatório e da qualidade da primeira consulta. ${ }^{5}$ Em relação ao acompanhamento no pré-natal e assistência à gestante e puérpera, o PHPN recomenda que sejam realizadas, no mínimo, seis consultas, sendo uma no primeiro trimestre, duas no segundo, três no terceiro trimestre da gestação, e uma consulta no puerpério (até quarenta e dois dias após o nascimento do bebê). ${ }^{6}$

[...] no postinho, perto da minha casa, fiz a primeira consulta e todos os exames necessários. Estava com três meses [...] fiz oito consultas até o sétimo mês [...] (Rosa).

Além do exame físico, a história da vida pregressa da gestante e os exames laboratoriais dão mais autonomia ao profissional de saúde na identificação de risco gestacional. Por isso, quando a demanda de serviço é maior que a oferta, o profissional deve atuar como facilitador no acesso da gestante ao serviço de referência, garantindo acompanhamento adequado às necessidades de saúde da gestante.

Nas falas abaixo, as gestantes relatam que acham importante aderir ao programa, visto já possuírem alguma doença, acreditando ser importante e seguro para a sua saúde e a do bebê acompanhar a gestação de forma mais próxima com uma equipe multiprofissional.

[...] acho que fui bem acompanhada. Além das consultas com o médico, participava do grupo de hipertensos, conversas com a psicóloga, nutricionistas e estagiárias de fisioterapia [...] (Violeta).

[...] foi muito satisfatório porque eu tenho problemas de diabetes, depressão, nefropatia e pressão alta. Eu vinha toda a quinta-feira no hospital dia (Lírio).

[...] lá no posto sou cadastrada e todos sabem que sofro de depressão e logo na segunda consulta fui encaminhada para o hospital dia. Aqui vinha uma vez por semana, fui bem atendida [...] (Cravo).
Os profissionais que acompanham a mulher no pré-natal, inclusive o enfermeiro, deverão elaborar um plano de assistência à gestante, de acordo com as necessidades identificadas e priorizadas, estabelecendo as intervenções, orientações, e os encaminhamentos a serviços de referência, promovendo a interdisciplinaridade das ações, com a medicina, odontologia, nutrição, serviço social e psicologia. ${ }^{6}$

Quanto às complicações que surgem na gestação, apontamos a hipertensão como contribuinte para a mortalidade materna e fetal. Salientamos que, no grupo de gestantes, são oferecidas as orientações necessárias quanto à prevenção de patologias que surgem no início da gestação. ${ }^{6}$

A implementação de grupos de gestantes é fundamental para garantir uma abordagem integral e, ao mesmo tempo, específica à assistência no período gestacional. ${ }^{7}$

No que se refere às doenças hipertensivas na gestação, torna-se importante a participação de uma equipe multiprofissional atuante, que busque estratégias para auxiliar a gestante na manutenção do peso, na reeducação alimentar - com uso de dieta hipossódica -, no controle dos níveis tencionais e na cautela no uso de medicamentos. Os sinais vitais aferidos, bem como o peso, medida abdominal (altura uterina), batimentos cardiofetais (BCFs) e vacinas ministradas, necessitam ser registrados na carteira da gestante e no prontuário. ${ }^{8}$

Em relação ao acompanhamento do pré-natal e assistência à gestante, $\mathrm{o}$ PHPN recomenda que a primeira consulta seja realizada até o quarto mês de gestação. ${ }^{6}$ Contudo, notamos, através do relato abaixo, que Margarida, não obteve acompanhamento no pré-natal.

[...] fiz uma consulta no posto e os exames que precisava. Fui atendida pelo médico, estava com cinco meses. Com seis meses eu não fui, achei que não precisava [...] (Margarida).

O agente de saúde, sempre que possível, deve intermediar as ações de saúde entre os profissionais do posto de saúde e a comunidade, com o intuito de promover vínculos e facilitar as relações interpessoais entre a comunidade e o serviço de saúde. O quanto antes a gestante for inserida no programa, maior serão as garantias de qualidades nas ações de saúde oferecidas.

O estabelecimento de vínculo entre a equipe multiprofissional e a gestante facilita as ações de saúde voltadas às suas necessidades de maneira integral. A mulher precisa sentir-se acolhida para ter segurança, e confiar na equipe de pro- 
fissionais. Essas condutas facilitam as relações interpessoais, e a assistência passa a ser integralizada, tornando o acolhimento humanizado e as ações de saúde de melhor qualidade. ${ }^{9}$ Por essa perspectiva, notamos maior adesão ao programa pelas mulheres entrevistadas.

Através da fala da Margarida, percebemos que ela não realizou o pré-natal por não sentir-se acolhida no posto de saúde perto de sua residência, além de não saber que poderia ter sido encaminhada para um hospital de referência.

[...] perto do sétimo mês comecei a ter cólicas. Eu fui lá no posto e não tinha médico. Como tinha ganhado o outro nenê no Presidente Vargas e fui bem atendida, eu vim aqui [...] (Margarida).

O PHPN está fundamentado no direito da humanização da assistência obstétrica e neonatal, além de estabelecer critérios de assistência qualificada, promovendo maior vínculo entre a assistência ambulatorial e maternidade de referência, com integralidade nas ações de saúde e efetividade nas intervenções. ${ }^{10}$

A mulher grávida deve receber atenção especial por parte dos profissionais de saúde, para manter e recuperar seu bem-estar, prevenindo dificuldades futuras com o filho. ${ }^{11}$

[...] aqui não recebi a atenção que recebi na vez passada [...] ninguém dizia nada, eu tava com muita dor, dor de parto [...]. Falei para a enfermeira que tinha dor e o que ia acontecer comigo. Ela foi grossa e disse: não fez o pré-natal, agora tá preocupada, pergunte ao médico [...]. Perguntei para um senhor mais velho se ele era o médico, ele disse que sim, mas mandou vários estudantes me examinarem (Margarida).

O Programa Nacional de Humanização à Assistência Hospitalar (PNHAH) estabeleceu como objetivo melhorar a eficácia e a qualidade da assistência e atenção dispensada aos usuários de rede hospitalar, capacitando os profissionais de saúde para um conceito de atenção baseada na valorização da vida humana, beneficiando os profissionais e o usuário do serviço de saúde. ${ }^{12}$

Os profissionais de saúde desempenham importante papel na atenção à mulher no ciclo gravídico-puerperal. Será importante que a mulher reconheça e sinta-se acolhida no processo de monitoramento e acompanhamento da gestação, beneficiando sua saúde e a de seu filho. De um modo geral, observamos, através das entrevistas, que as gestantes tiveram boa percepção do acompanhamento no pré-natal, evidenciada pelo número de consultas realizadas e pelas conversas informais na sala de espera, compartilhando com as demais o conhecimento recebido nas consultas.

\section{Segunda categoria: acesso, acolhimento e humanização}

O PHPN tem como princípio o direito ao acesso, com atendimento digno e de qualidade no período gestacional. ${ }^{6}$

Os estudos confirmam que o pré-natal realizado com qualidade e com assistência humanizada facilita o acesso da mulher e aumenta a adesão nas atividades propostas no pré-natal. ${ }^{9}$ A enfermagem deve exercer um papel fundamental nesse período, facilitando o acesso e atualizando as informações sobre o estado da gestante. ${ }^{13}$

[...] não conhecia nada aqui, aí a enfermeira do posto arrumou os papéis e a ambulância para eu vir. Tive sorte de ganhar vaga para ganhar o nenê aqui [...] (Rosa).

[...] consegui realizar minhas consultas e exames pedidos pelo médico aqui também. Logo que cheguei fui atendida e recebi medicação [...] (Violeta).

Acesso mais ou menos, ficavam muito longe e cansativo pra mim. Saía cedo de casa e ficava o dia inteiro aqui (Cravo).

Ao facilitar o acesso das mulheres aos programas de saúde, o profissional também estará qualificando a assistência, e realizando o acolhimento à gestante. Deverá oferecer respostas às dúvidas das futuras parturientes, e dar apoio à mulher, em decorrência do medo que a gravidez pode gerar, pois o acolhimento é um dos objetivos que norteiam o acompanhamento no pré-natal. ${ }^{14}$

A importância atribuída a participar ou não das consultas e atividades propostas pela equipe de saúde no pré-natal irá determinar o êxito do profissional e a qualidade de vida que a gestante deseja para si e família. Observamos que, embora os locais de assistência especializada às gestantes sejam distantes de seus lares, elas demonstram a importância que atribuem à participação, sendo assíduas nas consultas.

[...] no meu outro parto, há seis anos, era tudo mais difícil. Dessa vez não, fui bem atendida lá no posto, recebi encaminhamento para vir aqui no hospital [...] (Orquídea).

[...] foi muito bom o acolhimento lá no PSF e aqui [...] (Crisântemo).

[...] acolhimento lá posto foi bom, aqui o pessoal do dia é mais humano e acolhedor [...] (Violeta).

As falas acima evidenciam que os profissionais de saúde procuram acolher essas mulheres 
desde a confirmação da gravidez, preocupando-se com a saúde delas, esclarecendo suas dúvidas sobre as transformações com seu corpo e em relação ao neonato, tornando essa fase de transição tranquila para ambos. A puérpera precisa ser cuidada e acolhida durante todo o período de hospitalização, para não comprometer a qualidade do cuidado da mãe e do bebê. ${ }^{15}$

Nas falas abaixo, observamos que algumas mulheres vivenciaram algumas experiências de não-cuidado e até mesmo de negligência.

[...] com sete meses tive pressão alta e lá não podiam me atender. Na minha cidade não tinha este tipo de atendimento [para gestantes de alto risco]. Eu e meu marido não sabíamos o que fazer [...]. Eu tinha medo de esperar essa hora e meu filho morrer (Azaléia).

[...] ninguém me disse que lá na minha cidade não tinha lugar para ganhar bebê. Quando começou a dor do parto, fui lá no hospital e ninguém me atendeu, o guarda falou que era pra sair rápido de lá que não podia estacionar o carro ali, eu fiquei muito nervosa [...]. (Hortência).

[...] não sei, acho que não é humano viajar de ambulância quando está com dor, eu estava muito nervosa e tinha medo. Fiquei sozinha, não deixaram ficar acompanhante. Aqui disseram que parto normal não tinha direito e eu estava bem. Como pode uma mãe estar bem após um parto prematuro e o filho na UTI?[...] (Crisântemo).

O PNHAH foi criado em 1999, pela Secretaria da Assistência à Saúde do Ministério da Saúde, que se propôs a melhorar a eficácia na qualidade da atenção e assistência dispensada aos usuários, recuperando a sua imagem junto à comunidade. Para tanto, torna-se importante capacitar os profissionais da saúde para um conceito de atenção baseada na valorização da vida humana, oferecendo cursos de capacitação e especialização aos profissionais de saúde, o que deverá beneficiar os usuários dos serviços de saúde. ${ }^{16}$

Uma das estratégias encontradas pelo Ministério da Saúde na implantação do Programa Nacional de Humanização (PNH) foi incentivar a formulação de protocolos para o atendimento e serviço humanizado, apoiando as experiências encontradas na rede do SUS. Além disso, busca-se construir uma rede formadora e multiplicadora que melhore a ambiência dos serviços, tais como: ambiente confortável, mobília adequada, comunicação visual, acolhimento ao usuário, somando-se aos programas implementados pelo Ministério da Saúde e gestores estaduais e municipais. ${ }^{17}$

Em $1^{\circ}$ de janeiro de 2000, foi instituído, pelo governo federal, o PHPN, sob supervisão do Mi- nistério da Saúde, através da portaria GM n ${ }^{0} 569$, reforçando a necessidade de atenção à gestante, ao Recém-Nascido (RN) e à mulher no período pós-parto. Esse programa está fundamentado no direito à humanização da assistência obstétrica e neonatal como condição primeira para um atendimento eficaz, além de estabelecer critérios para uma assistência de qualidade, de promover um vínculo entre a assistência primária até o momento do parto, com integralidade nas ações de saúde e efetividade nas suas intervenções. ${ }^{6,10}$ Evidenciamos o comprometimento das instituições e dos profissionais nas falas a seguir:

[...] não tinha nada aqui. A enfermeira do posto arrumou os papéis e ambulância para eu vir. Tive sorte de ganhar a vaga para ganhar o bebê aqui (Rosa).

[...] era o meu terceiro parto, eu sei como é. Paramos em um posto policial e meu marido perguntou onde a gente poderia ir e o policial disse para eu ficar calma que ele saberia como resolver; me ajudou a entrar no carro da polícia, deu o endereço pra meu irmão no outro carro e trouxe eu e meu marido para cá (Hortência).

[...] desde a primeira vez que vim aqui fui bem recebida e sempre podia fazer os exames que o médico pedia. Humanizado também pra mim como para meu filho. O pessoal daqui é muito atencioso (Cravo).

Ficou demonstrado nas falas das puérperas citadas no texto, que a tríade acesso, acolhimento e humanização é de vital importância para a qualidade de assistência prestada à mulher, não só no período gestacional como em toda a sua vida. Além disso, proporciona o estabelecimento de estratégias com vistas a aprimorar as ações de saúde na atenção básica, para fazer valer os princípios do SUS.

\section{Terceira categoria: acompanhamento dos profissionais de saúde no pré-natal}

Quanto aos profissionais de saúde que acompanharam as entrevistadas no pré-natal, seis participantes responderam que foram acompanhadas por enfermeiras e médicos; enquanto que cinco puérperas foram acompanhadas por enfermeiras, médicos, especialistas, psicólogos, nutricionistas, fisioterapeutas, auxiliares e acadêmicos de enfermagem.

Uma das ações recomendadas pelo Ministério da Saúde ao Programa Saúde da Mulher é a assistência qualificada e humanizada dispensada à mulher durante o pré-natal, parto e puerpério.

Um estudo realizado com puérperas na cidade de Fortaleza evidenciou que a maioria das 
mulheres sente-se satisfeita em relação ao serviço e à qualidade do atendimento, sobressaindo-se a atenção, a confiança e o respeito dos profissionais. A minoria que apresentou insatisfação destaca a demora no atendimento e as dificuldades/negligência na comunicação, pois a linguagem é difícil e são muitas informações e desencontros nos conteúdos. ${ }^{18}$

A assistência prestada à gestante no pré-natal deve ocorrer de modo integralizado e focado em suas necessidades de saúde e comunicação efetiva, garantindo uma gestação mais segura, conforme os relatos a seguir:

[...] achei a assistência boa. Lá no posto, quando a enfermeira achou que eu precisava de um médico, me encaminhou para o médico, mas ele achou que eu precisava de acompanhamento obstétrico de alto risco e me encaminhou para cá [...] (Orquídea).

[...] a assistência foi de boa qualidade [...] quando um profissional não podia resolver um problema de minha saúde, passava para outro profissional e rapidinho se resolvia. Eles se preocupam com a gente (Cravo).

Será importante que o profissional de saúde comunique à gestante $a$ inclusão de outro profissional, bem como a necessidade dele no acompanhamento ao pré-natal. Essa aproximação estabelece vínculo, transmite confiança à mulher, diminui a ansiedade e faz com que a gestante se sinta valorizada. Uma equipe multiprofissional com bom relacionamento interpessoal apresenta maior autonomia para articular ações que contemplam a gestante, desde o início do pré-natal até o puerpério. ${ }^{19}$

[...] fui acompanhada pelo obstetra, nefrologista, psiquiatra, endócrino, psicólogas e enfermeiras. Foi muito bom, eles foram excelentes, passaram para mim segurança, foi com a ajuda deles que eu consegui ter meu filho (Lírio).

O pré-natal realizado por uma equipe multiprofissional tem se revelado excelente aliado à promoção da saúde, prevenindo transtornos psicoafetivos, transtornos alimentares e socioculturais da gestante, melhorando, assim, a qualidade da assistência materna e do recém-nascido. Também previne agravos, proporciona melhor qualidade de vida e auxilia a diminuir os riscos de morbimortalidade materna e fetal. ${ }^{20}$

\section{Quarta categoria: a visibilidade do enfermeiro no pré-natal}

De acordo com a Lei do Exercício Profissional da Enfermagem, Decreto n ${ }^{\circ}$ 94.406/87, o pré-natal de baixo risco pode ser acompanhado pelo enfermeiro. $\mathrm{O}$ enfermeiro elabora o plano de assistência de enfermagem na consulta de pré-natal, de acordo com as necessidades identificadas e priorizadas, e estabelece as intervenções, orientações e encaminhamentos a serviço de referência, quando necessário. ${ }^{6}$

[...] fui atendida primeiro pela enfermeira. Quando estava com a pressão alta fui atendida pelo médico [...]. Foi bom o atendimento (Jasmim).

A interação enfermeiro/gestante no período do pré-natal, parto e puerpério deve estar fundamentada no diálogo, na sensibilidade e afetividade, no prazer em desenvolver o cuidado humanizado, promovendo o vínculo, e proporcionando bem-estar fisiológico e mental à gestante. ${ }^{21}$

[...] lá no posto, participava de um grupo com outras gestantes. Além da enfermeira e o médico, também vinham nutricionista, psicólogo e estagiários de enfermagem e fisioterapia (Violeta).

[...] fui bem acompanhada por enfermeiras $e$ médicos. Acho que recebi o atendimento necessário. As enfermeiras me ensinaram a amamentar e cuidados com o bebê e comigo (Crisântemo).

O enfermeiro utiliza estratégias para estimular a presença da gestante no pré-natal. Através deste espaço de discussão, dá-se a continuidade da consulta de enfermagem, onde o enfermeiro realiza orientações sobre dieta, higiene, cuidados com as mamas, alterações corporais e emocionais, sinais e sintomas do parto, planejamento familiar, sexualidade e direitos trabalhistas. ${ }^{6}$

Através da anamnese, o enfermeiro poderá analisar os dados referentes à saúde pregressa da gestante, para então poder orientá-la, estabelecendo condutas de enfermagem pertinentes a cada mulher, conscientizando-as para o cuidado consigo, contribuindo para que a gestação transcorra naturalmente, com melhor qualidade de vida e garantia de uma vida saudável para o filho que irá nascer. ${ }^{22}$

\section{Quinta categoria: finalizando o pré-natal na maternidade}

A garantia de uma assistência adequada significa prevenir, diagnosticar e tratar eventos indesejáveis que possam ocorrer durante a gestação. Com o nascimento, devem ser introduzidos novos hábitos de vida e de saúde para a mulher, o filho e a família, para evitar a ocorrência de problemas comuns que possam vir a acontecer na hora do parto, ou, até mesmo, a falta de cuidado com o recém-nascido, por falta de informação. ${ }^{14}$

A familiaridade entre os profissionais de saúde e as usuárias do sistema é de extrema im- 
portância, para que ocorra a adesão da gestante aos programas de saúde, propiciando vínculo e humanização da assistência. As falas abaixo reproduzem o vínculo e a aproximação entre profissionais e gestantes:

[...] foi bom, já conhecia aqui. Como sabiam que estava sozinha e longe de casa me deram muito apoio (Cravo).

[...] fui muito bem atendida, muito bem preparada, acho que eles, os profissionais de saúde, fizeram o possível e o impossível por mim (Lírio).

[...] eu achei que não ia ser bem tratada, aqui está sempre lotado, mas todos foram muito atenciosos comigo e com o bebê (Orquídea).

O Ministério da Saúde instituiu o PHPN, que propôs mudanças na assistência à mulher, implementando a humanização nesse processo, melhoria na qualidade da atenção à gestante e firmando garantias e direitos às mulheres gestantes, visando realizar um atendimento digno e de qualidade na atenção à mulher, no parto e no puerpério. ${ }^{23-24}$

A OMS preconiza a mulher no período gestacional, com um pré-natal de qualidade, independentemente de a gestação ser classificada como de baixo ou alto risco. As mulheres devem ter garantias e direito ao atendimento, além do acesso às unidades de referência, atendimento ambulatorial e hospitalar se a gestante for de alto risco. ${ }^{4}$

Em relação à qualidade da atenção no pré-natal, a realidade nos mostra que a assistência, por si só, não garante bons resultados. ${ }^{25}$ Fica evidenciado pelas falas que, apesar de todos os programas que o governo federal institui para saúde da mulher, a qualidade da assistência prestada ainda é fragmentada, focando apenas a gestação, e desconsiderando o PHPN.

[...] me mandaram para casa, tomar Buscopam para as cólicas e ficar deitada. Quando cheguei em casa duas horas depois [de ter alta], tava com sangramento. Tomei um Buscopam e deitei, logo comecei a ter dor tipo contração. A vizinha chamou a SAMU, que demorou uns trinta minutos. Eu comecei a sangrar mais. Quando cheguei no hospital, logo ganhei prematuro meu filho [...] (Margarida).

[...] ontem, quando vim aqui com dor de parto, eles me examinaram e disseram que faltava quatro semanas. Na madrugada começou a dor novamente. Meu marido foi na prefeitura pedir a ambulância. Quando a ambulância chegou pela manhã, eu já tinha ganhado o bebê de oito mês (Dália).

[...] fiquei muito triste com o atendimento. $\mathrm{Na}$ minha cidade não tinha atendimento para parto. Acho que as pessoas que trabalham na área da saúde têm que ajudar mais porque são mais estudadas. A gente só procura ajuda porque não sabe o que fazer [...] (Hortência).

Observamos nos relatos, a tristeza das entrevistadas ao relembrar que foram aconselhadas a retornar para seus lares, arriscando a saúde de seus filhos. Notamos que ainda existem fragilidades com relação ao acolhimento, ao cuidado humanizado e à capacitação da equipe. Finalizar o pré-natal na maternidade é tão importante quanto o cuidado dispensado à gestante no pré-natal, pois um cuidado complementa o outro.

\section{CONSIDERAÇÕES FINAIS}

Ao concluir o presente estudo, verificamos que, na primeira consulta da gestante, a equipe de saúde deverá proporcionar informações claras, seguras e atender à mulher de forma integral e acolhedora, engajando-a ao serviço. Isso influenciará positivamente na decisão da gestante em realizar o acompanhamento no pré-natal. Percebemos que alguns fatores auxiliam nessa decisão, como: disponibilidade de acesso ao serviço, oferta de exame confirmatório, qualidade da assistência prestada pelo serviço público de saúde, empatia pela equipe e estabelecimento de vínculo com os profissionais de saúde.

Embora o acompanhamento para gestante de risco seja oferecido em Porto Alegre, em uma instituição de referência para o estado do Rio Grande do Sul, as gestantes enfrentam dificuldades quanto ao acesso geográfico, e por sua situação socioeconômica. Mesmo assim, não medem esforços para garantir assistência especializada na promoção à sua saúde e prevenção de agravos para o seu filho. O cuidado realizado às gestantes pela equipe multiprofissional mostra-se relevante nesta pesquisa, pois evita e previne agravos, proporcionando melhor qualidade de vida à gestante e, consequentemente, diminuindo os riscos de morbimortalidade materna e fetal.

O enfermeiro, ao receber a mulher para a confirmação da gestação, assume importante papel ao desenvolver ações de saúde no pré-natal, prevenindo, protegendo, recuperando e promovendo a saúde. Através dos resultados dessas ações desenvolvidas com as gestantes, o enfermeiro poderá avaliar a qualidade da assistência prestada.

Entendemos que este estudo possa subsidiar ações que contribuam para o planejamento de assistência que contemple a mulher gestante de modo integralizado, com perspectivas de cons- 
trução de novas propostas de saúde, envolvendo equipe multiprofissional de saúde, gestores e instituição pública de saúde.

\section{REFERÊNCIAS}

1. Organização Mundial da Saúde. Estratégias do PHPN. 1996 [acesso 2010 Abr 05]. Disponível em: http://www.saude.ms.gov.br/index. php?templat $=$ vis\&site $=116 \& i d \_c o m p=914 \& i d$ reg $=3533 \&$ voltar=lista\&site_reg=116\&id_comp_ orig $=914$

2. Minayo CS. O desafio do conhecimento: pesquisa qualitativa em saúde. $12^{\mathrm{a}}$ ed. São Paulo-Rio de Janeiro: Hucitec-Abrasco; 2004.

3. Conselho Nacional de Saúde (BR). Resolução 196/96, de 10 de outubro de 2006. Diretrizes e normas regulamentadoras de pesquisa envolvendo seres humanos. [acesso 2010 Mai 10]. Disponível em: http://conselho.saude.gov.br/resolucoes/ reso_96.htm

4. Ministério da Saúde (BR). Pré-natal e puerpério: Atenção qualificada e humanizada. Manual técnico. Brasília (DF): MS; 2006.

5. Ministério da Saúde (BR). Portaria $\mathrm{n}^{\circ} 572$ de $1^{\circ}$ de junho de 2000. Institui o Programa de Humanização, Parto e Nascimento no âmbito do Sistema Clínico de Saúde. Diário Oficial da República Federativa do Brasil, 18 ago 2000. Seção 1 [acesso 2009 Abr 20]. Disponível em: http://www.spp.org.br/ Portaria_572_GM.pdf

6. Pascoal IF. Hipertensão e gravidez. Rev Bras Hipertensão 2002 Jul-Set; 9(3):256-61.

7. Reberte LM, Hoga LAK. O desenvolvimento de um grupo de gestantes com a utilização da abordagem corporal. Texto Contexto Enferm 2005 Abr-Jun; 14(2):186-92.

8. Ceccon C, Eisenstein E. Saúde, vida, alegria: manual para educação em saúde de adolescentes. Porto Alegre (RS): Artmed; 2000.

9. Delfino MR, Patricio ZM, Martins AS, Silverio MR. O processo de cuidar participante com um grupo de gestantes: repercussões na saúde integral individual-coletiva. Ciênc Saúde Coletiva 2004 Dez; 9(4):1057-66.

10. Serruya SJ, Lago TG, Cecatti JG. O panorama da atenção pré-natal no Brasil e o Programa de Humanização do Pré-natal e Nascimento. Rev Bras Saúde Materno-Infantil 2004; 4(3):269-79.

11. Maldonado MT. Psicologia da gravidez: parto e puerpério. 16a ed. São Paulo (SP): Saraiva; 2002.
12. Ministério da Saúde (BR). Série C, projetos, programas e relatórios n. 20. Brasília (DF): MS; 2001 [acesso 2009 Abr 10]. Disponível em: http:/ / bvsms. saude.gov.br

13. Braden PS. Enfermagem materno-infantil. Rio de Janeiro (RJ): Reichmam e Affonso, 2000.

14. Rodrigues DP, Silva RM, Fernandes AFC. Ação interativa enfermeiro-cliente na assistência obstétrica. Rev Enferm UERJ 2006; 14(2):232-38.

15. Sarmento R, Setubal MSV. Abordagem psicológica em obstetrícia: aspectos emocionais da gravidez, parto e puerpério. Rev Ciência Médica 2003 Jul-Set; 12(3):261-8.

16. Martins MCF, Bogus CM. Considerações sobre a metodologia qualitativa como recurso para o estudo das ações de humanização em saúde. Saúde Soc 2004 Dez; 13(3):44-57.

17. Ministério da Saúde (BR). HumanizaSUS: Política Nacional de Humanização: relatório de atividades 2003. Série C, projetos, programas e relatórios. Brasília (DF): MS; 2003 [acesso 2009 Abr 20]. Disponível em: http:/ / portal.saude.gov.br

18. Queiroz MVO, Jorge MSB, Marques JF, Cavalcante AM, Moreira KAP. Indicadores de qualidade da assistência ao nascimento baseados na satisfação de puérperas. Texto Contexto Enferm 2007 Jul-Set; 16(3):479-87.

19. Peduzzi M. Equipe multiprofissional de saúde: conceito e tipologia. Rev Saúde Pública 2000 Fev; 35(1):130-9.

20. Falcone VM, Mäder CVN, Nascimento CL, Santos JMM, Nóbrega FJ. Atuação multiprofissional e a saúde mental de gestantes. Rev Saúde Pública. 2005 Ago; 39(4):612-8.

21. Rodrigues DP, Silva RM, Fernandes AFC. Ação interativa enfermeiro-cliente na assistência obstétrica. Rev Enferm UERJ. 2006 Jun; 14(2):232-38.

22. Duarte SJH, Andrade SMO. Assistência pré-natal no Programa Saúde da Família. Rev Esc Enf Anna Nery. 2006 Abr; 10(1):121-5.

23. Silva WVA. A qualidade da comunicação do profissional de saúde na assistência pré-natal. Santos (SP): Leopoldianum; 2001.

24. Almeida CAL, Tanaka OY. Perspectiva das mulheres na avaliação do Programa de Humanização do Pré-Natal e Nascimento. Rev Saúde Pública. 2009 Fev; 43(1):98-104.

25. Koffman MD, Bonadio IC. Avaliação da atenção pré-natal em uma instituição filantrópica da cidade de São Paulo. Rev Bras Saúde Materno-Infantil. 2005 Dez; 5(1):23-32. 